\title{
Liver hydatidosis in the present decade
}

Liver hydatidosis, a parasitic endemic disease affecting extensive areas in our planet, has been for decades a topic of debate in multiple medical and surgical forums because of its incidence, nonspecific symptoms, and diagnostic modalities, as well as the surgical procedures devised to solve this condition.

On the other hand the relevant complications that may arise with disease progression and may involve multiple organs and neighboring structures causing disruption, migration, contamination, etc., turned this disease into a significant stigma within medicine, enrolling healthcare providers (veterinarians, internists, radiologists, surgeons, etc.) who for decades attempted to reduce its incidence, find better diagnostic modalities, control its spreading, and provide new therapies in order to achieve a more optimistic view of the problem.

In our country, endemic areas existed for many years where incidence and prevalence rates were high, which was reported in a 1987 publication including over 7000 surgically-treated liver hydatidosis cases, the largest series reported in the medical literature worldwide to that day (1).

New diagnostic procedures (ultrasounds, scanners), new anti-parasitic therapies (albendazole), and novel surgical procedures (PAIR, radical surgery) emerged over the years, which have clarified and significantly improved long-term results $(2,3)$.

In the first report (1) of surgical treatment data, conservative surgery (marsupialization, lay-open, partial cystectomy, etc.) represented $65 \%$ of cases, and was associated with high morbidity. Mortality (2.3\%) was similar for both radical and conservative surgery.

Several years later, in a smaller series of patients by Servicio Nacional de Salud hospitals, radical surgery was $72.7 \%$ and conservative procedures had boiled down to $28 \%$. Mortality for conservative surgery persisted around $2 \%$ and was nil for radical surgery (4).

In the last few years hydatidosis has considerably changes in many respects, from diagnostic strategies to treatment approaches $(2,3)$, not forgetting new presentation forms and complications. The development of clinical therapy guidelines (5) and of evidence-based medicine (6) has spread among the medical community concepts that we all should bear in mind when suggesting an elective therapy for this condition.

New diagnostic modalities (ultrasonography, 3D scanner, MRI, ability to assess liver function, etc.) have led to new considerations and added accuracy to both cyst and liver functional assessment, providing new ideas for effective treatment. In this respect, this same issue of our Journal includes a retrospective study assessing the possibility of leaving selected (asymptomatic) liver cysts untreated with only followup (7). As it is a retrospective, observational review, its scientific value is hardly relevant given its limitations and small number of patients; however, it represents an interesting viewpoint to be considered in a near future. 
Medical treatment with antiparasitic drugs (albendazole or derivatives), while initially endorsed with substantial interest has provided no significant benefits, and potential serious complications (liver toxicity, bone marrow aplasia, etc.) greatly restrict its use (8-10).

Similarly, the fact should be borne in mind that serious complications secondary to chronic, prolonged hydatidosis have emerged in recent years, including secondary biliary cirrhosis, secondary biliary sclerosis, cholangitis, Budd-Chiari syndrome, and postnecrotic cirrhosis, which have subsequently needed wide resective surgery or even a liver transplant (11).

What is the role of laparoscopic surgery in the management of hydatidosis? It was initially highly promising but expectations set in early reports could not be corroborated afterwards (12-15). On the other hand, conservative surgery or PAIR (Puncture, Aspiration, Instillation, Re-aspiration) has not improved outcomes, and morbidity and mortality remain similar to those reported during the 1980s (16-18).

Our crucial question should be "Which therapy would be most appropriate and effective for liver hydatidosis in the upcoming decades?

Our answer is straightforward in reference to countries where modern, advanced medicine is practised, and where specific issues are treated by expert groups obtaining outstanding benefits. To this day surgery is the most effective treatment, and radical surgery (total cystectomy, hepatectomy) is the modality yielding the best results (19).

Regarding liver diseases, a high number of hospitals have medico-surgical hepatology units that satisfactorily solve conditions such as chronic hepatitis, liver tumors, etc., using surgical approaches where huge liver resection (hepatectomy, trisegmentectomy, etc.) entails no or little morbidity and mortality $(20,21)$ based not only on refined surgical techniques but also diagnostic tests (volume CT, MRI, angiography, etc.) that allow thorough knowledge regarding lesion size, location, and relations to intrahepatic vascular and biliary structures, as well as liver function. The above leads to a significant decrease in postoperative morbidity, as evidenced by a number of scientific papers (20-22). The clearest example of reduced morbidity in liver surgery is living-donor liver transplantation, where a liver portion (usually from a relative) is transplanted to a receiver. Donor hepatectomy entails no secondary problems in most cases.

If we translate these data into liver hydatidosis, an obvious question emerges: "What barriers prevent this condition from being managed in liver units?

There is logically no contraindication except in patients with other concomitant diseases rendering wide resective surgery a contraindication (22).

Conservative surgery (partial cystectomy, puncture aspiration, PAIR, etc.) retain a substantial morbidity, which is reflected not only by worse outcomes with higher relapse rates, but also by long-term complications that may jeopardize patient quality of life.

Therefore, in our view a patient with liver hydatidosis should be studied using the appropriate tests to reach an accurate diagnosis in terms of size, location, etc., allowing insight into the liver's functional capacity (ultrasounds, CT, MRI), and then undergo radical surgery, if possible by an expert team.

To conclude, it should be remembered that this proposal must be supported not only with medical aspects but also from an ethical standpoint, and perhaps the criminal liability often involved in current medicine.

Manuel Hidalgo, Eduardo Ferrero, José Perea and Ana Hidalgo

Department of General and Digestive Surgery B. Hospital Universitario 12 de Octubre. Madrid, Spain 


\section{REFERENCES}

1. Hidalgo M, Barquet N. Hidatidosis hepática: Estudio de una serie de 7.435 casos. Parte I: Aspectos generales, epidemiología y diagnóstico. Rev Esp Enferm Dig 1987;71:1-6. Parte II: Tratamiento quirúrgico. Morbi-mortalidad, tratamiento médico, hospitalización e implicaciones socio-económicas. Rev Esp Enferm Dig 1987;71:103-9.

2. Brunetti E, Junghanss T. Update on cystic hydatid disease. Current Op Inf Dis 2009;22:497-502.

3. Brunetti E, Kern P, Viutton DA, Writing Panel for the WHO-IWGE. Expert consensus for the diagnosis and treatment of cystic and alveolar echinococcosis in humans. Act Trop 2010;114:1-16.

4. Moreno E, Rico P, Bercedo J, García JI, Palma F, Hidalgo M. Results of surgical treatment of hepatic hydatidosis. Current therapeutic modifications. World J Surg 1989;15-2:254-63.

5. WHO Informal working group on echinococcosis. Guidelines for treatment of cyst and alveolar echinococcosis in human. Bulletin WHO 1996;74:231-4

6. Dziri C, Haouet K, Fingerhut A. Treatment of hydatid cyst of the liver. Where is the evidence? World J Surg 2004:28:731-6.

7. Ramia JM, de la Plaza R, Casares M, Ramiro C, Veguillas P, Quiñones J, et al. Profile of patients with hepatic hydatid disease not treated surgically. Rev Esp Enferm Dig 2011;103(9):448-52.

8. Cobo F, Yarnoz C, Aizcorbe M, Trujillo R, Díaz de Liaño, et al. Intraabdominal hidatidosis: does preoperative treatment with abendazole or abendazole-praziquantel affect the patient s hepatic function? Archv Internat Hidatidosis 1997;32(259):2.

9. Saimot AG. Medical treatment of liver hydatidosis. World J Surg 2001;25:15-20.

10. Bildik N, Cevik A, Altintags M, Ekinci H, Canberk M, Gulmen M. Efficacy of preoperative albendazole use according to months in hydatid cyst of the liver. J Clin Gastroentol 2007;41:112-6.

11. Loinaz C, Moreno E, Gómez R, García I, González-Pinto I, Jiménez C, et al. Liver transplantation in liver disease: echinococcus granulosus. Tranplantation Proceeding 1998;30:3268-9.

12. Manterola C, Fernandez O, Muñoz S, Vial M, et al. Laparoscopic pericystectomy for liver hydatid cysts. Surg Endosc 2002;16:521-4.

13. Kayaalp C. Evacuation of hydatid liver cyst using laparoscopy trocar. World J Surg 2002;26:1324-7.

14. Ertem M, Karahasanogh T, Yavuz N, Erguney S. Laparoscopically treated liver hydatid cysts. Arch Surg 2002;137:1170-3

15. Baltar JB, Baamonde JT, Concheiro PC, Varcia Vallejo LA, Brenlla J, Escudero PB. Laparoscopic treatment of hepatic hydatid cysts: techniques and postoperative complications. Cir Esp 2009;86:33-7.

16. Smego RA, Bhatti S, Khaliq AA. Percutaneous aspiration-injection-reaspiration drainage. A meta-analysis Clin Infest Dis 2003;37:1073-83.

17. Priego P, Nuño J, López Hervas P, López RA, Peromingo R, Díez J, et al. Hidatidosis hepática. Cirugia radica vs. no radical. 22 años de experiencia. Rev Esp Enferm Dig 2008;100(2):82-5.

18. Mosca F, Stracqualuigi F, Persi A, Angiello A, Latteri S. Surgical treatment of hepatic hydatidosis. Analysis of results of conservative and radical surgery in our experience. Chir Ital 2003;55:1-12.

19. Alonso Casado O, Moreno E, Loinaz C, Gimeno A, González Pinto I, Pérez Saborido B, et al. Results of 22 years of experience in radical surgical treatment of hepatic cysts. Hepatogastroenterology 2001;48:235-43.

20. Robles R, Marin C, Fernández JJ, Ramírez P, Sánchez-Bueno F, Morales D, et al. Hacia la mortalidad cero en las resecciones hepáticas. Presentación de 200 casos consecutivos. Cir Esp 2005;78:19-27.

21. Yuksel O, Akyurek N, Sahin T, Salman B, Azili C, Bostanci H. Efficacy of radical surgery in preventing early local recurrence and cavity related complications in hydatic liver disease. J Gastrointest Surg 2008;12:483-9.

22. Ramia JM, Figueras JF. Hidatidosis hepática. ¿Qué técnica debemos realizar? Cir Esp 2010;88:1-2. 